\title{
Collaborative Approaches for Self-Organized Competence Development
}

\author{
Heiko Matheis, Jennifer Lucke, Meike Tilebein
}

\section{Introduction}

The ongoing digital transformation is changing work and production environments. While this leads to adaptation pressures, it also offers potential for competitive advantages. Particularly small and medium-sized enterprises (SMEs) in the European textile industry are confronted with numerous challenges associated with the digital transformation. Moreover, this sector is traditionally characterized by global competition and rapid changes in trends and markets. Under these general conditions, demand-oriented development and efficient use of competences, both individual and organizational, are becoming ever more important for success.

Accordingly, this paper covers competence development approaches on individual and organization level. The latter comprises both intra-organizational and interorganizational activities and processes facilitating self-organized development of competences on firm level, e.g. by supporting collaboration in networks. The individual level includes activities and processes that can be directly linked to value creation on the shop floor. Hence, employees' individual competences are in focus.

On individual level on the shop floor there is a high degree of pressure on employees and their managers to adapt to changing conditions. The pressure on employees to adapt their competences is primarily driven by small production lot sizes, shorter product life cycles and faster technological advancements that quickly devalue relevant knowledge, and by fundamental change in value creation processes due to the digital transformation (Bauernhansl et al. 2018). Additional pressure results from a shortage of skilled workers and from challenges arising from the significant demographic and cognitive diversity of the workforce.

The Research Council of the Platform Industry 4.0 published a study investigating the research and development needs for the successful implementation of Industry 4.0. This acatech-study calls for new approaches to competence development and employee qualification, offering a differentiated view on leadership functions in various hierarchical, horizontal or network contexts. The study further illustrates how new decentralized and situationally adaptable solutions that enable self-orga 

nized learning paths and informal competence development are becoming a necessity for all actors in the industrial production process to acquire essential competences (Forschungsbeirat der Plattform Industrie 4.0 2019).

As much as the concept of individual competence development provides a valuable approach for the upcoming scenarios, one has to bear in mind that individual competences unfold their full potential in situations that foster their combination and interaction. Trough collaboration, complex problems can be approached and solved.

Approaches to support self-organized learning paths and dynamic, role- and actorbased models for collaborative knowledge generation already exist on organization level. There they have proven to be worthwhile, especially when considering SMEs with their specific environments and innovation processes (Matheis 2019). At the Center of Management Research of the German Institutes of Textile and Fiber Research Denkendorf (DITF), corresponding approaches for the textile industry and related sectors have been developed in recent years (Matheis et al. 2017; Matheis, Lau, Hirsch, \& Tilebein 2014). From these, findings can also be transferred to production processes on shop floor level.

This paper presents challenges of collaborative competence development and approaches to solve them on different levels of the organization. Also, it explains specific implementations based on project examples.

In Section 2, the paper provides an overview of the challenges and drivers associated with competence development under the digital transformation. It describes technical advancements due to the digital transformation, as well as relevant societal trends. Afterwards, it considers resulting challenges for competence development on different organizational levels.

In Section 3, the general aspects of competence development are put into the specific context of the textile industry. After a short portray of that industry the general challenges described in Section 2 are reflected from the perspective of textile companies.

In Section 4, the paper reports first solutions towards collaborative approaches for self-organized competence development for the textile industry that match the needs and challenges described in Section 3. In detail the concepts of Smart Networks and the research projects InnoQuality, TexWIN, and TELL ME serve to demonstrate sample solutions on organization and individual level respectively. To bridge the gap between those two levels, new leadership models and the concept of self-organized learning paths present suitable approaches to implement the concept of self-organized competence development.

Finally, Section 5 summarizes the paper and points towards avenues for further research. 


\section{Challenges and Drivers for Competence Development Under the Digital Transformation}

\subsection{General Drivers}

At present producing companies are faced with shorter product life cycles and faster technological advancement that lead to a constant need for innovation. The focus thereby moves towards increased individuality in products and services. The employees in development and value creation processes not only have to handle the increasing variety of customer-specific products, but also innovations in production processes and technologies. This way, routines have to be adapted permanently and novel competences to deal with new technical systems have to be developed (Forschungsbeirat der Plattform Industrie 4.0 2019).

German producing companies, and SMEs in particular, have a long-standing tradition in highly specialized value creation. Their development and production activities are based on knowledge-intensive processes and knowledge work featuring high complexity and continuous innovation. In this area specific work-related experiences and creative problem-solving skills of employees are highly in demand. At the same time, an academization trend is taking place. More young people than ever are pursuing a university degree, thereby replacing other forms of education such as apprenticeships or dual training programs which further increases the need for automation in production. (Hertle et al. 2015) Furthermore, demographic change accounts for greater diversity as well as greater differences in society and workforces (Hilf \& Tilebein 2013).

Given these conditions, ongoing adaptation and learning becomes essential. Turning to customer-specific products which are characterized by unique orders and individual requirements, learning becomes particularly necessary. While fixed routines are still applicable on the overall process level, specific problems arising from each individual order differ from each other. (Hube 2005)

While the digital transformation accelerates the ongoing changes by increasing the pressure on organizations to adapt, it also provides opportunities to manage these changes. Assistance systems can for example provide help by supporting staff in value creation processes. (Bauernhansl et al. 2014)

On the technical side, decentralization and self-organization in the areas of interaction, information processing and decision-making are relevant principles of Industry 4.0 applications. These principles bear great advantages for system adaptability, robustness and resilience.

However, so far the application of these principles has mainly focused on the technical subsystems of the Industry's socio-technical systems. In order to make their socio-technical systems thrive as wholes, companies have to embrace the new chances arising from the digital transformation and to permanently develop their 
competences according to need throughout all organizational levels. (Adam et al. 2019; Vernim et al. 2019)

\subsection{Competence Development on Organization Level}

On organization level, it is the organization's task to identify, develop and use competences in order to enable innovation and organizational learning. Organizational competences are complex high-level organizational routines that meet specific market requirements. In this sense, they are valuable resources that can contribute to maintain a sustainable competitive advantage. Thus, from an organization's view, a main challenge resulting from the changes mentioned above is to integrate and embrace staff and competence diversity on all organizational levels. Diversity should be turned into a resource for competence development and renewal and for gaining competitive advantage in the ever-changing environment of the digital transformation, while balancing exploitation and exploration. (Tilebein 2007)

In addition, the constant need for innovation in combination with an increasing digitization of products and processes requires companies to acquire new competences outside of their core competences. Competence development through learning from other experts and the ability to collaborate within networks are therefore becoming key to successful innovation (Mazzerol \& Reboud 2008; Nonaka et al. 1997).

However, in order to integrate external knowledge companies face the challenge of opening their own processes to customers, suppliers, complementors and competitors (Dooley \& O’Sullivan 2007; Müller-Seitz 2012). Considering competences and information as a resource, mere access to competences and information is usually not sufficient to achieve competitive advantage. This means that the competence to cooperate with partners in networks is becoming more and more important and, through the resulting exchange of knowledge, is increasingly becoming the key to successful collaboration (Lau \& Tilebein 2013).

Temporary innovation networks are formed featuring a collaborative and projectlike environment. These networks are further characterized by a variety of autonomously acting participants with different goals, cultures and work contexts (Camarinha-Matos \& Afsarmanesh 2005). In order for such a dynamic network to be temporarily successful, new competences in leadership and self-organization of all participating actors to coordinate and control the activities within the collaboration are essential.

Various concepts address these missing collaboration competences on organization level. Agile management, actor-oriented architecture, Smart Organization and Smart Networks derived from the latter are concepts already introduced utilizing an agile, actor-oriented, and role based approach to collaborative work (Filos 2006; Fjeldstad et al. 2012; Lau et al. 2015). However, the successful implementation of 
these dynamic network concepts depends on the ability of companies to develop new competences in these novel collaborative forms of value creation. This comprises learning new tools, processes and methods.

Looking at the concept of Smart Networks in particular, initial approaches on how innovation processes in smart networks can be supported from idea to market launch are described (Matheis, Tilebein, Hirsch, \& Lau 2014). In these dynamic networks actors can take different roles over time, which results in the need for dynamic positioning of all participants. This presents the challenge of developing actor specific as well as situation and process specific competences.

\subsection{Competence Development on Individual Level}

The general drivers described in Section 2.1 also affect individual competence development of production personnel on the shop floor (Tenberg \& Pittich 2017). The activities in production are changing in terms of complexity and frequency of renewal. Renewal in this sense describes activities with which employees are confronted for the first time and for which they cannot fall back on approved solutions from own experience-based knowledge (Hube 2005). Complexity and novelty are the two defining dimensions of the concept of so-called "knowledge work". This form of work is required when activity-related problems cannot be solved routinely and are highly complex.

A first challenge when it comes to individual competence development is to provide a reliable measurement system of competences in socio-technical production systems. This is necessary to find a balance between available and needed competences (Jacobs et al. 2021). Such a measurement could build the basis for a competence development process including the phases of learning initiation, interaction, cognitive problem solving, operational solution implementation and reflection on the performance of the activity (Sobbe et al. 2016). In addition to implementing a dedicated competence development process, designing a structured approach to identify the required competences of employees with respect to future work conditions (for example the usage of assistance systems, digital assistants, or exoskeletons) presents a challenging task. (Vernim et al. 2019)

A second challenge regarding individual competence development is to enable situation specific work-based learning (Jacobs et al. 2021). Consequently, "knowledge work" must be implemented in the form of informal but intentional work-based learning in order to promote competence development. In this context, technological and methodological support could enhance competence development.

Thus, providing technological support for work-based learning is a driver, but also a challenge for individual competence development. In any innovation context there are barriers to overcome. In the context of individual competence development this means to create technological solutions which are accepted by the employees and furthermore foster the motivation for situation specific work-based 
learning. Therefore, ergonomically accentuated digital assistance systems can be used to provide information that specifically support employees in problem solving, decision making and reflecting on solutions (Adam et al. 2019).

\section{Specific Situation in the German Textile Industry}

\subsection{General Overview of the Textile Industry}

The German textile industry, one of the most important consumer goods sectors (BMWI 2021; Umweltbundesamt 2019), is characterized by a large number of differently positioned SMEs and by operating under cost pressure. With its more than 1,400 companies, it generates an annual turnover of around 32 billion euros (of which around 60\% account for textiles and 40\% account for apparel), making it the market leader in Europe. In particular, small and medium-sized enterprises (SMEs) characterize the textile and clothing industry; 93\% of all companies have less than 250 employees. Besides the clothing sector, the German textile industry is supplier for several other industries such as the rubber and plastic industry, the automotive industry, mechanical engineering, the electrical industry, and the construction industry. (Textil+mode 2021a, 2021b)

Being a supplier industry, the German textile industry has to cope with a wide range of requirements from various customer industries. In this situation the textile industry benefits from the flexibility of the existing textile machinery, that is basically able to handle different materials such as traditional textile semi-products as well as new textile products like carbon fibers or metal wires. Thus, textile manufacturing processes offer a multitude of possibilities, if the industry succeeds to close the gap between technical possibilities, integration requirements and necessary competences. (Artschwager et al. 2017) T

he capability of the textile industry to combine traditional and "new" materials is related to traditional frequent changes in customer behavior and market structure. The German and European textile industry undertook a major change in the fields of application. It turned from mass production to knowledge intensive products for new markets and high technology applications such as smart textiles, medical devices or lightweight structures. Therefore, the development of new business models such as collaborating with other sectors is a key success factor for modern companies in the textile industry. (Tilebein 2017)

The general development in the manufacturing industry towards lean processes and structures has resulted in highly specialized companies also in the textile industry. The expertise within the companies, which are often times SMEs, is limited to specific process stages. However, increasing customer requirements and increasing complexity often require knowledge exchange across several process stages. (Artschwager et al. 2017) 
Similar to other industries, the textile and clothing industry is in the midst of a digital transformation, which requires a fundamental structural change of organizations, processes, and information and communication technology (ICT) infrastructures. While the current ICT infrastructure of companies often is designed for specialized and self-contained activities within the organization, the digital transformation now also enables digital exchange with partners and customers in dynamic networks. Nevertheless, the current systems are neither designed for this nor do the employees have the corresponding competences. Furthermore, the demographic situation within the textile and clothing industry together with the decline in qualified workers requires new solutions for work-based competence development. (Artschwager \& Tilebein 2017) Thus, in the textile industry, just like in the producing industry in general as sketched in Section 2, there is a strong need for approaches towards competence development on organization as well as on individual level, and in the alignment of the two.

\subsection{Challenges on Organization Level: Product and Process Innovation}

High value-adding processes for knowledge-intensive textile products and services are facing growing complexity and therefore call for close partnerships. Especially for companies which are increasingly acting across sectoral borders functional as well as technical interoperability has become tremendously important. Only by trustful collaboration between partners, required knowledge and competence can be acquired, shared and used to develop targeted innovative products and services for new customers and target markets. However, even after including the right partners in the first phases of development, companies have to ensure that competences gained in these early steps will be available throughout the whole product life cycle in order to guarantee the efficient and sustainable production of products and/or the delivery of valuable services. (Dooley et al. 2016)

Furthermore, continuous work-based competence development is of great value also for the next generation of products and services, due to the extremely growing complexity of scientific, technical, and business requirements for high value products and services. Competence development has thus to be recognized and treated as valuable resource within textile companies and across their network of partners and should be supported by appropriate ICT structures. (Filos 2006)

Consequently, significant challenges in particular for SMEs emerge. The first challenge is to establish a network for the development and production of knowledgeintensive products and services. Therefore, the identification of the knowledge and competences needed throughout the product life cycle is crucial. The requirements towards partners can change due to the evolution of various needs and opportunities. The network requires flexibility to handle such dynamics. Changes in partnerships or roles of partners should have no or very limited influence on the management of those collaborations. Therefore, the competence of leading employees should enable a robust and flexible organization. (Filos 2006; Matheis et al. 2017) 
The involvement of customers in the development processes increases the complexity of product and service designs. Without proper monitoring of the development status and resources in a network, the efficiency of the development processes can decrease and costs can increase dramatically (e. g. many development iterations due to permanently changing requirements). Networking and the idea of open innovation require a strong support of SMEs and in particular of their employees in all tasks arising in the product life cycle. (Du Chatenier et al. 2010)

Another challenge for SMEs is to cope with the management and transformation of knowledge along the product life cycle. During the process knowledge and competences from various partners are used to form new knowledge. Competence development has to deal explicitly with the availability of the required competence at the right time but also with the conservation of new competences for later phases of development and production.

\subsection{Individual Level: New Challenges on the Shop Floor}

The ongoing transformation of the textile industry accounts also for fundamental intra-organizational changes in engineering and production.

As an example, the Digital Textile Micro Factory features end-to-end integrated digital design and production processes and can therefore be regarded to as a milestone for the textile industry on its way to Industry 4.0 (Tilebein 2019). However, the Micro Factory comes with a new set of challenges to be addressed. This new process provides a range of possibilities including completely new business models in the areas of individualization, sample production, reordering and event-driven production (Deutsche Institute für Textil- und Faserforschung 2019).

At the beginning of this process scanning devices and smart services allow for individualized product configurations (Artschwager \& Tilebein 2017). Putting the customer in a central position and fostering direct communication directs the whole design process towards the customer and extends the value chain into the market. Customers are becoming prosumers, who are empowered to design their own products by themselves (Moltenbrey \& Tilebein 2020). These individualized garments do not only cover different body shapes and sizes, but also play an important role when it comes to physical disabilities. Here, Digital Textile Micro Factories create the necessary diversity to outfit all individuals (Artschwager \& Tilebein 2017). At the same time, the production systems themselves are becoming smart. Being equipped with a range of sensors, the production machines can independently monitor their current status within the production process and manage their maintenance schedule with the help of predictive maintenance algorithms (Artschwager \& Tilebein 2017).

In spite of integrated digital technologies people remain at the center of all these developments. The digital transformation in socio-technical systems stresses the importance of skilled employees and their individual knowledge. In line with that, 
the need for ongoing competence development through work-based learning is increasing steadily. (Artschwager \& Tilebein 2017)

\subsection{Bridging the Gap from Individual to Organization Level}

The needs sketched above in terms of organizational competences, which are required for using the innovation capability of dynamic networks, and individual competences, that have to be acquired especially with regard to new digital technologies and individualized products, have to be addressed by competence development activities on either level, be it individual or organization level.

In addition, since a large part of organizational competences in the textile industry is based on personal competences of experienced staff, the individual and the organization level have to be aligned properly. This bears a specific challenge for firms not only in terms of their competence development strategies, but also in terms of their strategies for competence utilization.

At the same time, the textile industry in Germany is experiencing a particular shortage of skilled workers. Many experienced employees will retire in the next few years due to the industry's age structure, while a lack of industry attractiveness leads to recruiting problems in Germany. The reason for this missing attractiveness is that the textile sector in Germany, despite its transformation into an innovative hi-tech industry, still struggles with a poor reputation and an outdated image from the perspective of potential employees. This is why textile companies face a broad range of diversity in their workforce, in terms of e.g. age, skills, cultural background, industry or workplace experience, affinity towards ICT etc.

Against this background, companies in the textile industry need to rethink their strategies for competence identification, competence development and competence utilization and look for appropriate methods and tools supporting these strategies.

\section{Solutions and Open Research Questions for Collaborative Approaches for Self-Organized Competence Development for the Textile Industry}

\subsection{Solutions on Organization Level}

The concept of collaboration in networks is already being used extensively in terms of cooperation between companies. Hereby, they work together in temporary and variable compositions. Especially for small companies with very specific competences this approach is a model for success. The concept of Smart Networks which 
was developed in the EU funded project SmartNets ${ }^{1}$, describes an industrial model to support SME collaboration in the day-to-day business of SMEs. This model is applicable along the complete product life-cycle of different industry sectors. The implementation of this industrial model into practice is based on several methods and tools. Therefore, the methods have a clear focus on SME suitability considering a clearly described and easy to follow process complemented by examples. Furthermore, most of the developed methods are accompanied by tools which act as assistance systems that allow a self-organized learning of the methods during application. (Lau et al. 2015)

The successful implementation of the role- and actor-based model within Smart Networks depends on the ability of SMEs to know their exact position within the process as well as possible next steps at any time throughout the collaboration project. The Smart Net Collaboration Model builds the frame for the Smart Networks industrial model by orchestrating activities within the process, actors within the network and methods to be applied. Thus, the Smart Net Collaboration Model provides answers to key questions like "What to do next?", "Who can do it?", "Which method could help me?". (Lau et al. 2015)

One of the tools to support the implementation of the collaboration model is the Smart Net Navigator which supports the self-organization of specialists and managers across company boundaries as well as self-organized learning and application of the underlying innovation process. This digital assistance system helps actors to navigate through the ongoing innovation process by monitoring their current position within the innovation process and finding the answers to the above mentioned key questions on "actors to involve", "methods to apply" and "steps to perform". Thus, the Smart Net Navigator fulfills both the function of a project cockpit, which determines and displays the current project status, and the function of an advisor and trainer, who points out possible next steps in the process and suggests the methods required for this and other actors to be involved. (Matheis et al. 2014)

In addition to engaging in the self-organized application of a given innovation process as well as navigating through one, configurating a generic innovation process in an assisted but self-organized and needs-based approach presents the next step. To address this need was the goal of the project InnoQuality ${ }^{2}$. As a result of

1 The European research project „, SmartNets - The Transformation from Collaborative Knowledge Exploration Networks into Cross Sectoral and Service Oriented Integrated Value Systems" (CP-FP 262806; SmartNets) aims to establish and to prove 'Smart Networks' as a holistic industrial model for sustainable and efficient production in cross-sectoral SME collaboration both in development and production of knowledge-intensive products and services.

2 The collective research project " Improving the Quality of Innovation Projects in the

Field of Interior Textiles" (IGF $116 \mathrm{EN}$; InnoQuality) aims at optimizing the innovation funnel at interior textile companies. 
this project, for the textile industry and in particular for the home textiles sector an interactive guideline was presented that supports and accompanies companies in the home textile industry in the description, evaluation and processing of development projects. With the guide, managers from the development area can design the development process themselves depending on the particular technical and organizational challenges of their respective framework conditions in order to ensure innovation quality even with complex requirements. The interactive guide follows a case-study based approach to identify success factors for innovation and the associated process configuration. In this context, the transfer of knowledge from past successful, but also from unsuccessful innovation projects plays a decisive role in the success of future innovation projects. Beside the implicitly transferred knowledge through suggestions of the guide, this concept uses the method of storytelling to explicitly explain why considering specific success factors is crucial for specific project designs. (Matheis et al. 2017)

In line with the benefits of this approach on organization level, the principles of collaboration in networks and of self-organized problem-specific process configuration can also be transferred to lower organizational levels. Implementations can take place on all levels including the shop-floor level to establish a work-based competence development through self-organized learning paths.

4.2. Solutions for Digital Assistance Systems for Work-Based Competence Development on Shop Floor Level

The German industry and in particular the textile industry currently experience a development in value creation towards increasing knowledge work while at the same time routine activities are becoming less frequent. This ultimately leads to a scenario in which every order is unique and requires a specific process solution as laid out in the context of the Micro Factory in Section 3.3. Employees performing the processes therefore need to be equipped with opportunities to work out individual solutions immediately. The concept of lifelong learning is still applicable in this context. However, instead of taking place off-site during educational trainings, this new form of learning happens directly during the value creation process. This way value creation and learning merge into work-based learning making continuous competence development the preferred approach. Being referred to as "learning on demand" this new approach requires not only self-determination, but also self-direction from the learners. The opposing idea of "learning ahead" on the other hand is losing importance. Since the content and time frames of competences to be acquired differs from individual to individual, self-organized learning paths provide an optimal solution to that. (Hertle et al. 2015) Within the textile industry there are some new concepts for work-based learning in pilot scale already 
elaborated and evaluated. The first concept which was developed within the European research project TexWIN ${ }^{3}$ applies a case-based reasoning method mainly to combine human experience with information from other sources to improve the stability of production processes even for individually designed products. The underlying digital assistance system supports the employees in their work through pre-selected information while the decision-making authority remains with them. Case-based reasoning as an assistance system can be integrated easily into the production processes of textile companies, because the process of case-based reasoning has long been part of the daily work of many employees also in a non-digital form. It is the process of using former experiences and adapting them to new, similar situations. In the textile industry it is applied, for example, to determine initial machine settings for new or modified products or the adjustment of machine settings during operation in the event of poor performance or frequent process downtimes. Even if workflows using ICT-supported case-based reasoning are hardly different from conventional workflows, their implementation in the dayby-day business in not trivial. The employees have to be convinced to share their individual knowledge with their colleagues to individually benefit from the knowledge within the company. Thus, a living case-based reasoning system supports the workers on the shop floor in their individual competence development through the collaboratively filled case base. (Weiß et al. 2017)

Within the framework of TELL ME ${ }^{4}$ a second solution for work-based learning was developed, which focuses on the assessment of different technologies and learning methodologies. The framework aims at variable processes with knowledge work in various industries and tested ICT applications and assistance systems at the production level in helicopter and yacht construction as well as in the textile industry. In helicopter construction in particular, the consortium developed and tested a specially developed ICT-supported process model for knowledge work in the area of maintenance and services, which focused on demand-oriented learning when leaving routine processes. In the textile industry, software supported precision teaching for fabric inspection and the detection and correction of faults in particular - especially new types of faults from different fields of application were addressed. Using the method of precision teaching employees learn appropriate correction measures when certain faults occur as well as basic correlations and technical vocabulary. Compared to conventional training methods, this approach leads to a significantly shorter training time and better comparability of learning

3 In the European research project "Textile Work Intelligence by closed-loop control of product and process quality in the Textile Industry" (CP-FP 246193-2 TexWIN), textile research institutes as well as textile companies and textile machinery manufacturers were involved as users of the solutions developed. of the textile machinery industry were involved as users of the developed solutions.

4 The European research project „Technology-Enhanced Learning Livinglab for Manufacturing Environments" (CP 318329 TELL ME) aims to develop and trial an innovative cross-enterprise methodology and IT platforms for continuous education and training in small and medium manufacturing environments for work-based competence development. 
results. A second technology-based approach tested with in the textile industry was an augmented reality application for the set-up of weaving machines. Since setting up weaving machines is knowledge-intensive and time-consuming, the use of augmented reality (AR) facilitates the set-up-process and the retrieval of specific information. The process steps and explanations are simply superimposed on the AR glasses and the worker is guided through the entire process in this way. (Winkler et al. 2015)

Since assistance systems and human-machine collaboration have to be adapted to specific workplace requirements, individual and customizable designs are essential. Additionally, systems need to be able to evolve in line with changing conditions and different user demands. Central questions in this regard that remain to be answered include how to deal with topics of liability and servantship in socio-technical systems.

4.3. Open Questions Regarding the Alignment of Individual and Organizational Competence Development

As sketched above, companies in the textile industry need to rethink their overall strategies for competence identification, competence development and competence utilization. Specific solutions and tools already exist both on organization and on individual level. However, these are not aligned. Strategies are needed that balance top-down central approaches with self-organized bottom-up decentral approaches and fit to and align different organizational levels. Additionally, these strategies should integrate and support aspects of human interaction and collaboration, as it is the case in interorganizational innovation processes, as well as human-machine collaboration, and largely digitalized knowledge-intensive processes just like in the Micro Factory.

The respective strategies should build upon and make use of staff and competence diversity as a resource. The focus ultimately lies on the cognitive diversity of employees which arises from their different skills and talents. This diversity and its interconnectedness make innovative and creative solutions possible in the first place.

These strategies also require a new understanding of leadership. Similar to the shift from centralized information processing and control towards decentralized decision-making in technical systems that is one of the basic ideas of Industry 4.0, there is a need for corresponding models for the human-related parts of the socio-technical systems that are involved in any of the industry's processes.

Complex adaptive systems are agent-based systems that exhibit emergence. This term describes the generation of macro-level properties arising from self-organized micro-level interactions without them being planned or foreseen. Complexity science's theoretical perspective is far from generating a comprehensive and ready- 
to-use solution for the challenges described above. However, it can provide a useful integrative framework and complex adaptive system models offer a valuable theoretical approach towards new insights into self-organized competence development. Complexity leadership theory (CLT) describes the corresponding leadership theory which allows to use the principle of emergent qualities from self-organized interactions throughout all organizational levels and with their respective organizational actors (Uhl-Bien et al. 2007).

In the CLT framework, which is explicitly depicted as a new leadership paradigm for knowledge-generating organizations, a distinction is made between three basic leadership functions that are called administrative leadership, adaptive leadership, and enabling leadership. Administrative leadership includes classic management tasks such as planning, coordination, goal setting, resource allocation, conflict resolution and the like. Adaptive leadership ensures the adaptability of the system under consideration. This function focuses on the emergent quality of leadership and its emergence from interaction processes of actors. The drivers of these processes are the actors' heterogeneity and asymmetries, which are present not only in the classic sense in terms of power, but also in terms of knowledge, skills, and so on. In relation to adaptive leadership, enabling leadership finally has a catalytic function and thus has the task of creating framework conditions in which adaptive leadership can show itself and develop. The possibilities from the spectrum of administrative leadership can also be used for this purpose.

In the area of administrative leadership, certain aspects like fostering an integration in the organizational hierarchy and goal system, support the necessary alignment of individual learning on the shop floor level with external goals addressed. Turning to the adaptive leadership functions, on the other hand, links to self-organized, informal and collaborative learning processes and learning paths that are embedded in networks can be observed. Finally, enabling leadership contains the tasks of shaping, moderating and handling the area of tension emerging from the previous two leadership functions, depending on the situation.

The CLT framework can support the idea of using diversity as a resource and enabling self-organized collaborative learning and the emergence of new competences while aligning the respective processes throughout organizational levels.

\section{Summary and Outlook}

The ongoing digital transformation radically transforms work and production environments. For the manufacturing industry this means major adaptations become necessary to secure their competitiveness. For the textile industry, which mainly consist of SMEs and the German textile industry in particular, this implies the need to face the emerging challenges on top of the traditional challenges coming from global competition and rapid changes in trends and markets. 
Facing these challenges, the textile industry in Germany in particular will, due to an increasing number of retirements in the next years, face a broad range of diversity in their workforce. Consequently, solutions to promote the development of individual competences are necessary. In addition, personalization and increasing complexity of products or shortened technology and product life cycles influence traditional production activities on the shop floor. This ultimately leads to a scenario in which every order is unique and requires a specific process solution. Thus, a breaking of routines that typically lead to the learning of new workflows is the consequence. In particular lean and highly specialized SMEs in addition to their competence in developing specialized products increasingly need competences that go beyond their organizational borders. Therefore, focusing on core competences without supplementing them with organizational and individual competences for collaboration is no longer sufficient.

Hence, collaborative approaches for self-organized competence development according to individual needs on any organizational level are required. The industry needs concepts, methods and tools (e.g. digital assistance systems) to establish selforganized learning paths on every organizational level, from the organization level to the individual level on the shop floor, and to manage their alignment.

This paper presents some already existing solutions for work-based competence development on the shop floor as well as solutions for the development of organizational competences such as the capability to collaborate in networks. Nevertheless, there are still open questions to elaborate on. Future research topics include personalization and optimization of assistance systems, collaboration scenarios that consider all parts of socio-technical systems, as well as methods and tools for self-organized collaborative competence development throughout all organizational levels. They have to be complemented with leadership models that are able to bridge the gap and support the alignment of the different organizational levels.

\section{References}

Adam, C., Aringer-Walch, C., \& Bengler, K. (2019). Digitalization in Manufacturing - Employees, Do You Want to Work There? In S. Bagnara, R. Tartaglia, S. Albolino, T. Alexander, \& Y. Fujita (Eds.), Advances in Intelligent Systems and Computing. Proceedings of the 20th Congress of the International Ergonomics Association (IEA 2018) (Vol. 825, pp. 267-275). Cham: Springer International Publishing. https://doi.org/10.1007/978-3-319-96068-5_30

Artschwager, A., Tilebein, M., Rieder, O., Armbruster, P., \& Gresser, G. T. (2017). Textil digital: Die Zukunft der textilen Produktion am Beispiel des Strick-Clusters Baden-Württemberg. Retrieved from DITF - Deutsche Institute für Textil- und Faserforschung Denkendorf website: https://www.ditf.de/files/inhalt/startseite/Studie-Strick40.pdf 
Artschwager, A., Tilebein, M. (2017). Die Zukunft der textilen Produktion am Beispiel von Microfactories. Melliand Textilberichte. (1), 113.

Bauernhansl, T., Hompel, M. ten, \& Vogel-Heuser, B. (2014). Industrie 4.0 in Produktion, Automatisierung und Logistik: Anwendung · Technologien · Migration. Dordrecht: Springer.

Bauernhansl, T., Tzempetonidou, M., Rossmeissl, T., Groß, E., \& Siegert, J. (2018). Requirements for designing a cyber-physical system for competence development. Procedia Manufacturing, 23, 201206. https://doi.org/10.1016/j.promfg.2018.04.017

BMWI (2021). Textil und Bekleidung. Retrieved from https://www.bmwi.de/Redaktion/DE/Artikel/Branchenfokus/Industrie/branchenfokus-textil.html

Camarinha-Matos, L. M., \& Afsarmanesh, H. (2005). Collaborative networks: a new scientific discipline. Journal of Intelligent Manufacturing, 16(4-5), 439-452. https://doi.org/10.1007/s10845-0051656-3

Deutsche Institute für Textil- und Faserforschung (Ed.) (2019). Annual Report 2019: Textile Future [Special issue]. Retrieved from https://www.ditf.de/en/index/download.html

Dooley, L., Kenny, B., \& Cronin, M. (2016). Interorganizational innovation across geographic and cognitive boundaries: Does firm size matter? R\&D Management, 46(S1), 227-243. https://doi.org/10.1111/radm.12134

Dooley, L., \& O’Sullivan, D. (2007). Managing within distributed innovation networks. International Journal of Innovation Management, 11(3), 397-416.

Du Chatenier, E., Verstegen, J. A. A. M., Biemans, H. J. A., Mulder, M., \& Omta, O. S. W. F. (2010). Identification of competencies for professionals in open innovation teams. ReD Management, 40(3), 271-280. https://doi.org/10.1111/j.1467-9310.2010.00590.x

Filos, E. (2006). Smart Organizations in the Digital Age. In I. Mezgár (Ed.), Integration of ICT in smart organizations (pp. 1-38). Hershey, PA: Idea Group Pub. https://doi.org/10.4018/978-1-59140$390-6$

Fjeldstad, Ø. D., Snow, C. C., Miles, R. E., \& Lettl, C. (2012). The architecture of collaboration. Strategic Management Journal, 33(6), 734-750. https://doi.org/10.1002/smj.1968

Forschungsbeirat der Plattform Industrie 4.0 (2019, September 26). Themenfelder Industrie 4.0: Forschungsund Entwicklungsbedarfe zur erfolgreichen Umsetzung von Industrie 4.0 (Kooperationspublikationen). Retrieved from https://www.acatech.de/publikation/themenfelder-industrie-4-0/

Hertle, C., Siedelhofer, C., Metternich, J., \& Abele, E. (2015). The next generation shop floor management-how to continuously develop competencies in manufacturing environments. In The 23rd International Conference on Production Research, Manila, Philippines.

Hilf, G., \& Tilebein, M. (2013). Diversität in interorganisationalen Teams. Industrie Management, 29(3), $25-29$.

Hube, G. (2005). Beitrag zur Beschreibung und Analyse von Wissensarbeit (Dissertation). Universität Stuttgart, Stuttgart. https://doi.org/10.18419/opus-4050

Jacobs, J.C., Kagermann, H., Roehl, H., \& Spath, D. (2021, April 20). Dynamisches Kompeten₹management - Kompetenz̧bedarfe früb erkennen, passgenaue Angebote ableiten (acatech DISKUSSION). Retrieved from https://www.acatech.de/publikation/dynamisches-kompetenzmanagement/ 
Lau, A., \& Tilebein, M. (2013). Kompetenz des Netzwerks durch Kompetenz des Netzwerkens - Förderung der Netzwerkfähigkeit kleiner und mittlerer Unternehmen. In H. Biedermann (Ed.), Schriftenreibe der Hochschulgruppe für Arbeits- und Betriebsorganisation e.V (HAB). Corporate Capability Management: - Wie wird kollektive Intelligen₹ genutzt? (351--376). Berlin: GITO.

Lau, A., Tilebein, M., \& Fischer, T. (2015). The Industrial Model of Smart Networks for SME Collaboration. In M. Lauras, M. Zelm, B. Archimède, F. Bénaben, \& G. Doumeingts (Eds.), Enterprise Interoperability (pp. 139-145). Hoboken, NJ, USA: John Wiley \& Sons, Inc. https://doi.org/10.1002/9781119081418.ch19

Matheis, H. (2019). Wissensorientiertes Management kollaborativer Innovationsprojekte: Methodische und technologische Lösungen für einen kybernetischen Ansatz. Komplexität und Diversität in soziotechnischen Systemen: Vol. 6. Berlin, Münster: Lit.

Matheis, H., Fischer, T. V., \& Tilebein, M. (2017). Erfolgsfaktoren beim Innovieren - Fallstudien basierter adaptiver Leitfaden für die Textilindustrie. In H. Binz, B. Bertsche, W. Bauer, D. Spath, \& D. Roth (Eds.), Stuttgarter Symposium für Produktentwicklung 2017. Stuttgart: Fraunhofer Verl.

Matheis, H., Lau, A., Hirsch, M., \& Tilebein, M. (2014). Methods and Tools for Managing Diversity in Smart SME Networks in Collaborative R\&D Projects. In S. Schimpf (Ed.), Proceedings of the ReD Management Conference 2014: Connecting High V alue Solutions With Future Markets (pp. 133-140). Stuttgart: Fraunhofer Verl.

Matheis, H., Tilebein, M., Hirsch, M., \& Lau, A. (2014). Managing diversity of collaborative innovation projects. In 20th International Conference on Engineering, Technology and Innovation (ICE Conference) IEEE TMC Europe Conference, Bergamo, Italy.

Mazzerol, T., \& Reboud, S. (2008). The Role of Complementary Actors in the Development of Innovation in Small Firms. International Journal of Innovation Management, 12(2), 223-253. https://doi.org/10.1142/S1363919608001960

Moltenbrey, F., \& Tilebein, M. (2020). Potenziale und Herausforderungen neuer digitaler Interaktionssysteme im Kollektionsentwicklungsprozess der Bekleidungsindustrie. In M. Freitag (Ed.), MenschTechnik-Interaktion in der digitalisierten Arbeitswelt (pp. 59-78). GITO Verlag. https://doi.org/10.30844/wgab_2020_4

Müller-Seitz, G. (2012). Leadership in Interorganizational Networks: A Literature Review and Suggestions for Future Research. International Journal of Management Reviews, 14(4), 428-443. https://doi.org/10.1111/j.1468-2370.2011.00324.x

Nonaka, I., Takeuchi, H., \& Mader, F. (1997). Die Organisation des Wissens: Wie japanische Unternehmen eine brachliegende Ressource nutzbar machen. Frankfurt/Main: Campus-Verl. Retrieved from http://www.gbv.de/dms/faz-rez/F19980518BONUS--100.pdf

Sobbe, E., Tenberg, R., \& Mayer, H. (2016). Knowledge work in aircraft maintenance. Journal of Technical Education, 4(1), 81-97.

Tenberg, R., \& Pittich, D. (2017). Ausbildung 4.0 oder nur 1.2? Analyse eines technisch-betrieblichen Wandels und dessen Implikationen für die technische Berufsausbildung. Advance online publication. https://doi.org/10.48513/joted.v5i1.94

Textil+mode (2021a). Figures. Retrieved from https://textil-mode.de/en/newsroom/figures/

Textil+mode (2021b). konjunktur 04.2021. Retrieved from Confederation of the German Textile and Fashion Industry website: https://textil-mode.de/de/documents/1456/2021-04_Konjunkturbericht.pdf 
Tilebein, M. (2007). Theoriebeiträge der Komplexitätsforschung zum strategischen Kompetenz-Management. In J. Freiling \& H. G. Gemünden (Eds.), Jahrbuch strategisches Kompeten₹-Management: Band 1. Dynamische Theorien der Kompetenzentstehung und Kompetenzverwertung im strategischen Kontext (1st ed., pp. 49-77). München, Mering: Rainer Hampp Verlag.

Tilebein, M. (2017). New business models. IoTex - Technical Brief. (1), 38-39.

Tilebein, M. (2019). Small, Smart and Sustainable. Digital Textile. (2), 60-63.

Uhl-Bien, M., Marion, R., \& McKelvey, B. (2007). Complexity Leadership Theory: Shifting leadership from the industrial age to the knowledge era. The Leadership Quarterly, 18(4), 298-318. https://doi.org/10.1016/j.leaqua.2007.04.002

Umweltbundesamt (2019). Textilindistrie. Retrieved from https://www.umweltbundesamt.de/themen/wirtschaft-konsum/industriebranchen/textilindustrie\#die-textilindustrie-indeutschland

Vernim, S., Korder, S., \& Tropschuh, B. (2019). Sind unsere Mitarbeiter für einen Einsatz in der digitalen Fabrik richtig qualifiziert? Ermittlung zukünftiger Mitarbeiteranforderungen in der Smart Factory. In C. K. Bosse \& K. J. Zink (Eds.), Arbeit 4.0 im Mittelstand: Chancen und Herausforderungen des digitalen Wandels für KMU (1st ed.). Berlin, Germany: Springer Gabler.

Weiß, M., Fischer, T., \& Tilebein, M. (2017). Wissensorientierte Nutzung von Informationen im Industrial Internet of Things. In N. Gronau (Ed.), Schriftenreibe der Wissenschaftlichen Gesellschaft für Arbeits- und Betriebsorganisation (WGAB) e.V. Industrial Internet of Things in der Arbeits- und Betriebsorganisation (pp. 119-139). Berlin: GITO Verlag.

Winkler, M., Grau, G., \& Tilebein, M. (2015). Lebenslanges Lernen - Neue Ansätze für die Textilwirtschaft. In H. Meier (Ed.), Schriftenreihe der Hochschulgruppe für Arbeits- und Betriebsorganisation e.V. (HAB): Vol. 19. Lehren und Lernen für die moderne Arbeitswelt (pp. 15-38). Berlin: GITO. 